\title{
Fatal High Voltage Accidental Electrocution - Two Case Reports
}

Manigandan $\mathrm{G}^{1 *}$, Peranantham $\mathrm{S}^{1}$, Shanmugam $\mathrm{K}^{2}$

${ }^{1}$ Senior Resident, Forensic Medicine \& Toxicology, JIPMER, Puducherry - 605006, India

${ }^{2}$ Junior Resident, Forensic Medicine \& Toxicology, JIPMER, Puducherry - 605006, India.

\begin{abstract}
Electric accidents cause serious injuries by direct heat exposure or by igniting clothes. The severity varies between simple harmless shocks to death. Many at times the victims are thrown to ground from the electric poles sustaining fatal non electric injuries. In this article two cases of high voltage electrocution are reported and discussed. In the first case the victim sustained injuries due to arcing of current. In the second case, there were multiple exit wounds in both legs indicating two different directions in the flow of current. Both the victims suffered fatal head injuries due to fall.
\end{abstract}

Keywords: high voltage electrocution, arcing of current, multiple exit wounds

\section{*Corresponding Author:}

Manigandan G, MD.

Senior Resident, Forensic Medicine \& Toxicology, JIPMER,

Puducherry - 605006, India

Tel: 917598566989

E-mail:dr.manigandan86@gmail.com

Recieved: July 18, 2014

Accepted: August 16, 2014

Published: August 19, 2014

Citation: Manigandan G, Peranantham S, Shanmugam K (2014) Fatal High Voltage Accidental Electrocution - Two Case Reports. Int J Forensic Sci Pathol. 2(7), 57-60. doi: http://dx.doi.org/10.19070/2332287X-1400016

Copyright: Manigandan $\mathbf{G}^{\circ} 2014$. This is an open-access article distributed under the terms of the Creative Commons Attribution License, which permits unrestricted use, distribution and reproduction in any medium, provided the original author and source are credited.

\section{Introduction}

Man used fire as his main source of domestic energy in ancient times. Later with increased need and industrialization wind, water, coal, and lastly nuclear power sources are being used to produce energy. Today we don't know how we would survive without electricity. It has become an integral part in to the human life from household purposes, industrial works to production of other sources of energy. It has mingled with the lives of the people. But we should not forget the dangers involved in the usage of this invaluable energy source. Electric shock occurs when a sufficient amount of current passes through body parts by any source of electricity. Electric shock is usually caused by contact with frayed cords, poorly insulated wires, ungrounded electric instruments and working in electric posts without any protective guard. The severity varies from simple harmless shock to severe muscle contractions, unconsciousness and death. Sometimes the victims may be thrown to ground causing more fatal injuries. Electrocution results when a person is exposed to lethal amount of electricity and it involve both high voltage ( $>600$ to $750 \mathrm{~V}$ ) and low voltage $(<600 \mathrm{~V})$ currents. Virtually all cases of electrocution are accidental in nature, with suicides rare and homicides even rarer. We hereby report two cases of electric fatalities and show how danger is the electrical shock in outdoor setup.

\section{Case Report 1}

The victim was a 14 year old boy referred to our hospital casualty with history of sustaining electric shock while bird-nesting in an electric pole which is about 20 feet height from the ground level. Initially he was conscious, oriented and his vitals were stable, but gradually his condition worsened and died within 6 hours of admission in the hospital. His biochemical investigations were within normal limits. Autopsy revealed multiple burnt and punched out lesions involving left half of the trunk, inner aspect of left upper limb and inner aspect of both thighs including the genital region (Fig 1). On dissecting the head, fracture of left temporal and parietal bones were seen. Underlying the fracture extradural haemorrhage with blood clot weighing around 20 grams was found. Brain underlying the extradural haemorrhage was found to be depressed and the temporal lobe on the left side was contused.

\section{Case Report 2}

A 40 year old lineman had sustained electric shock and burn injuries while repairing high tension wires and was brought dead to casualty. The victim was wearing a cotton shirt and it caught fire during the incident. On autopsy burn injuries were seen over front of chest, abdomen and anterior aspect of both thighs, which were due to burning of his clothes. A charred and deeply scorched electric mark was found over the lateral aspect of the right index finger suggestive of the entry wound of the passage of current. Multiple exit wounds were seen over the pulps of all the toes of the right foot (Fig 2). A burn area of size $6 \times 3.5 \mathrm{~cm}$ was seen over the plantar aspect of the right foot suggestive of heating up of the tissues, dissolution of keratin and separation of epidermaldermal layers by the current. A deeply scorched wound was seen over the medial aspect of left foot (Fig 3). In this case the exit wounds are multiple and are seen in both the foot, indicating that the passage of the current is in two different directions. On opening the cranial cavity, extradural haemorrhage was seen over the left parieto-temporal area. Diffuse subarachnoid haemorrhage was seen in the left cerebral hemisphere along with contusion of 
Fig 1: Multiple burnt and punched out lesions involving trunk and genitalia

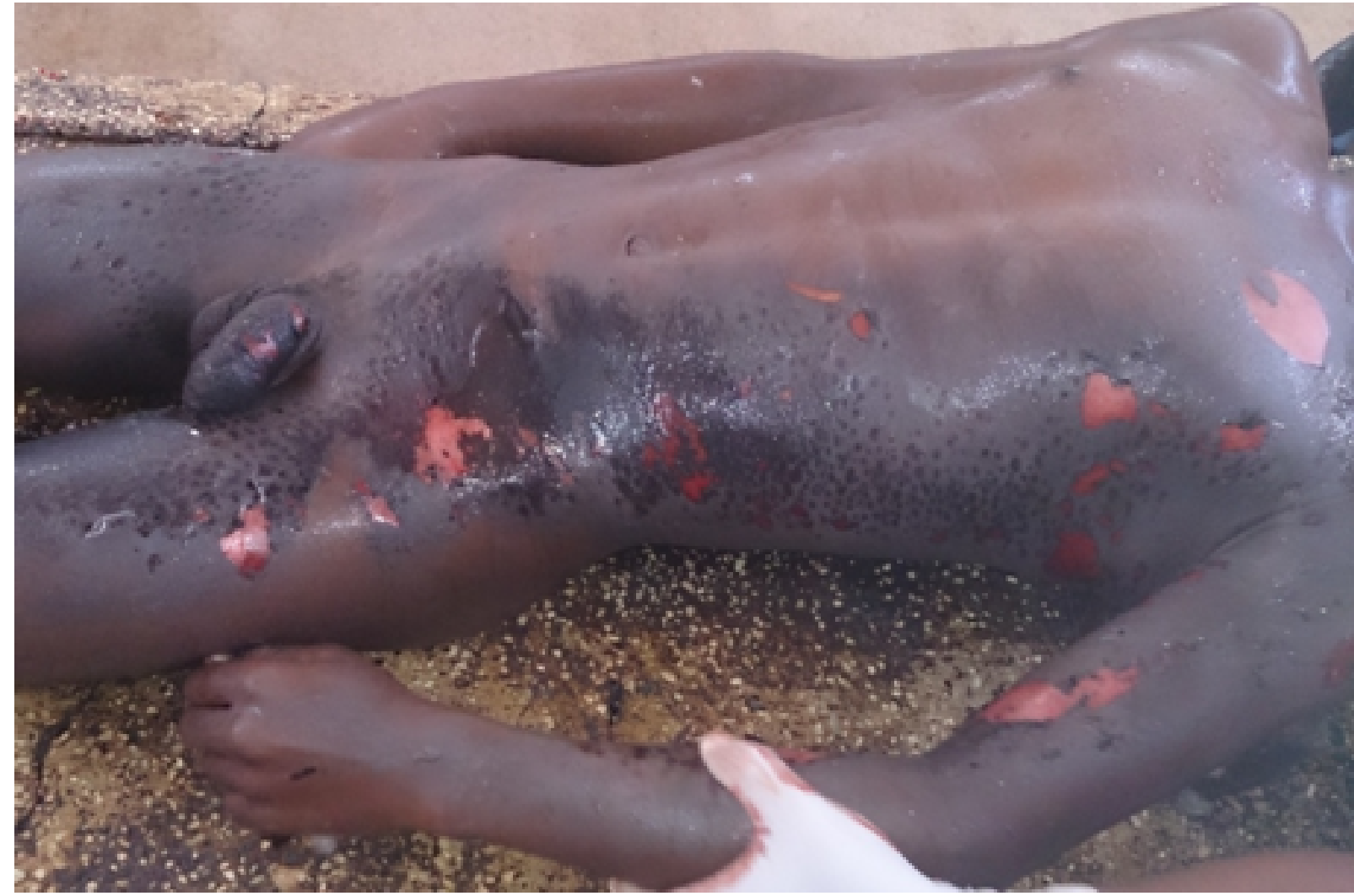

Fig 2: Multiple exit wounds of right foot

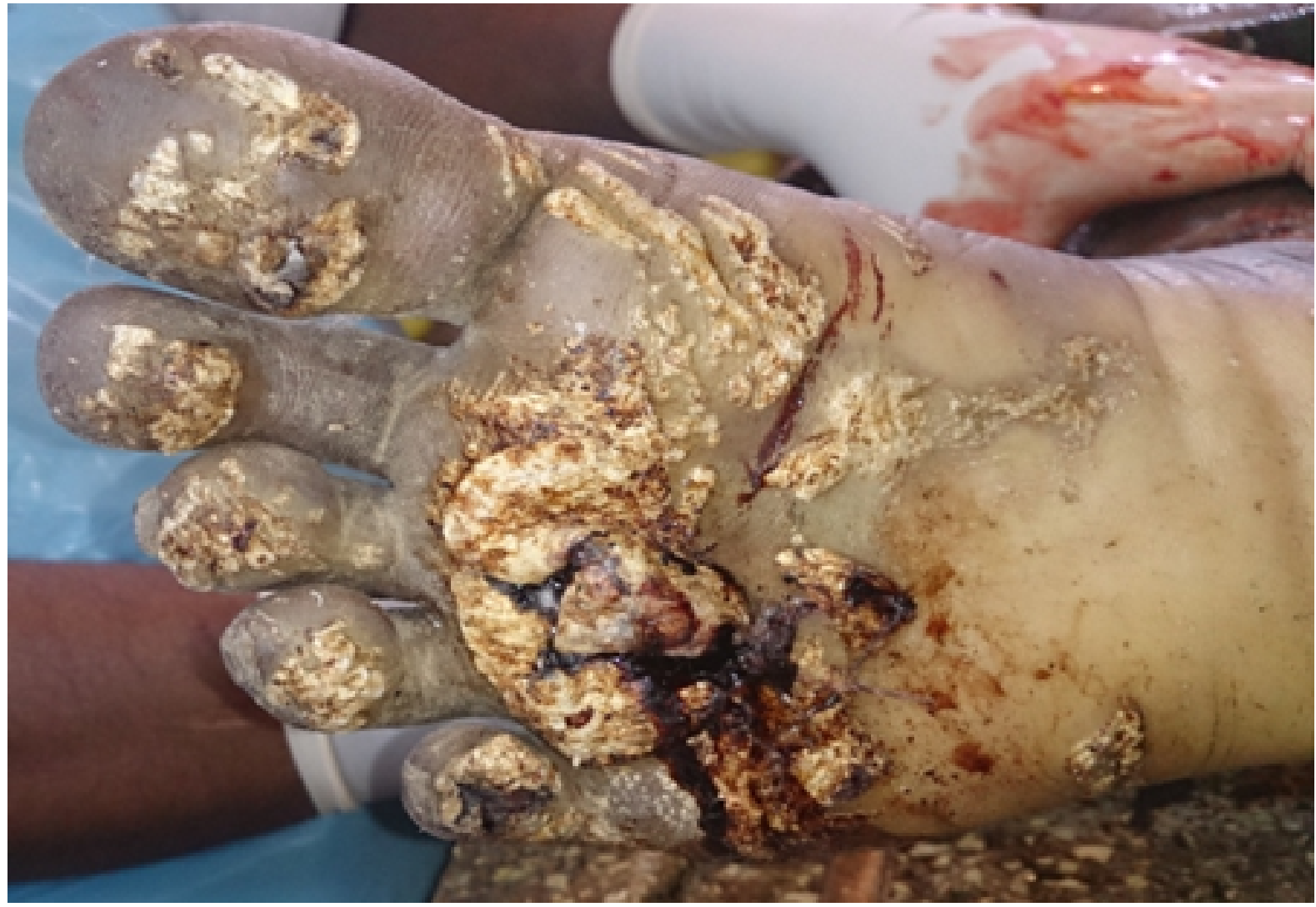


Fig 3: A deeply scorched wound over medial aspect of left foot

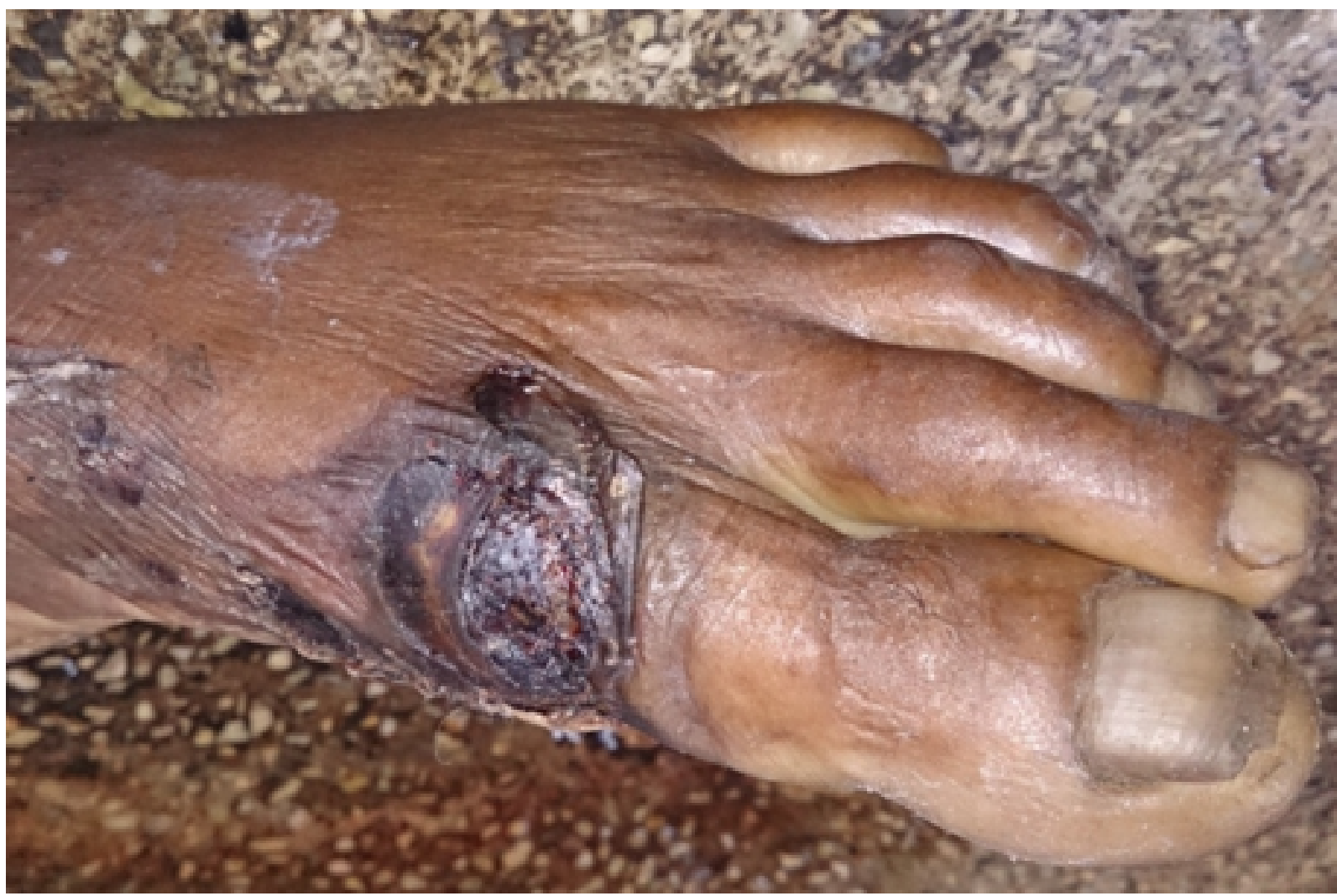

the temporal lobe without any fracture of the skull.

\section{Discussion}

In electrocution for death to occur, the human body must become a part of an active electrical circuit having current capable of over stimulating the nervous system or causing damage to internal organs[1]. The basic physics of electric current can be expressed by the formula: $A=V / R$. The terms $A C$ and $D C$ represents the flow of current. Direct current (DC) travels in one direction, and alternating current (AC) resulting from the changing direction of the electric flow[2]. The extent of injuries received depends on the magnitude of the current (measured in Amps), the pathway of the current, the duration of current flow and the resistance offered by the body. The most important factor in electrocution is the amperage or the amount of current flow. As the voltage (V) is constant, the main factor which determines the amount of amperes entering the body is the resistance offered by the body against the current. The minimal amount of amperage perceptible to a human as a tingle is $1 \mathrm{~mA}$, whereas $5 \mathrm{~mA}$ produces tremors and 15-17 $\mathrm{mA}$ causes contracture of the muscles, which prevents the victim from releasing the live conductor. Ventricular fibrillation occurs between 75 and $100 \mathrm{~mA}$ [3]. Extremely high currents do not cause ventricular fibrillation, but rather results in ventricular arrest. Most fatalities occur with the domestic voltage between 110 and $380 \mathrm{~V}$, which is the voltage range of houses and industrial electricity. The transmission (over 13,800V) and distribution (fewer than 13,800 V) lines typically carry the high voltages[4]. Skin offers higher resistance to the passage of current than internal tissues. The resistance $(\mathrm{R})$ varies greatly according to thickness of the keratin covered epidermis; so that palms, soles and calloused skin provide more resistance than the thin skin elsewhere. The resistance is also affected by the moisture present over the skin. With $120 \mathrm{~V}$, dry skin may have a resistance of 100,000 ohms; dry and calloused skin up to a million ohms; moist skin 1,000 ohms or less, and moist, thin skin as low as 100 ohms[5].Jaffe (1928) stated sweating could reduce skin resistance from 30000 to $2500 \mathrm{ohms}[6]$. Whereas, in high voltage currents skin condition plays no significant role in resistance.

Electric current takes the path of least resistance and creates heat, causing thermal damage to various tissues along its passage[3]. Most of the deaths from electricity are from cardiac arrhythmias, usually ventricular fibrillation leading to cardiac arrest. It is due to passage of current through the myocardium and possible dislocation of pacemaking nodes. Death may occur as a result of respiratory arrest, due to paralysis of intercostal muscles and diaphragm or rarely by affecting the brain stem, when the current enters through the head. But it must always be remembered that non-electrical trauma is quite common. With electric source of greater than $300 \mathrm{~V}$, current might be transmitted by means of arcing, caused by formation of conductive plasma between the source and the ground. The blast effect of high-voltage arcing can throw the victim away from the source, causing fatal injuries [2,7]. The distance to which an electric arc can jump is proportional to the voltage. The current can arc up to $35 \mathrm{~cm}$ in $100000 \mathrm{~V}$ or may be as little as few $\mathrm{mm}$ in $1000 \mathrm{~V}[8]$.

In case 1, there were no entry or exit wounds. The sustained burn injuries were due to arcing of the current, giving rise to the appearance of 'crocodile skin'. The victim suffered non-electrical injuries from being thrown to the ground. In case 2, both the entry and exit wounds were seen. In this case the exit wounds were multiple and much severe in nature. This extremely high voltage current causes the epidermal keratin to melt and, after cooling, it leaves a raised brown or yellow nodule of fused keratin sur- 
rounded by an areola of pale skin. Das $\mathrm{S}$ et al reported a case of high voltage suicidal electrocution with multiple exit wounds [9] Electrocution is an uncommon cause of death and occurs commonly due to accident[10]. Deaths due to electrical injuries are low when compared with deaths due to other causes. As the electric injuries involve multiple body systems, the entry and exit wounds fails to reflect true extent of the underlying tissue damage[11]. Injuries from high voltage electrocution pose a serious threat to life increasing the mortality rate. Most of the electrocution deaths are preventable in nature and they can be prevented by implementing proper educational programmes to the society including the electricity board workers with regard to the usage of safety appliances and insulators. Children should be taught about the dangers of electricity and importance of electric safety.

\section{Conflict Of Interest}

There is no conflict of interest, the author do not have financial or other relationship with other people or organization that may inappropriately influence the author's work.

\section{Acknowledgement}

We express immense gratitude in thanking the authors of various scientific articles published in different sites as well as reference books and journals.

\section{References}

[1]. Sheikhazadi A, Kiani M, Ghadyani M. Electrocution-related mortality: a survey of 295 deaths in Tehran, Iran between 2002 and 2006. Am J Forensic Med Pathol 2010;31:42-45.

[2]. Wesner ML, Hickie J. Long term sequelae of electrical injury: Clinical review. Canadian Family Physician 2013; 59.

[3]. Di Maio VJ, Di Maio D. Forensic Pathology. 2 nd ed. Boca Raton: CRC press; 2001

[4]. Kumar S, Verma AK, Singh US. Electrocution-related mortality in northern India - A 5-year retrospective study. Egypt J Forensic Sci 2013

[5]. Bruner JMR, Haazards of electrical apparatus. Anaesthesiology 1967; 28: 396-425.

[6]. Saukko P, Knight B. Forensic Pathology. In: London: Edward Arnold; 2004; 372

[7]. Pham TN, Gibran NS. Thermal and Electrical Injuries. Surg Clin N Am 2007;87: 185-206

[8]. Sornogyi E and Tedeschi CG, Injury by electrical force, in Tedeschi CG, Eckert WG, Tedeschi LG (Eds): Forensic Medicine. Philadelphia, WB Saunders Co 1977;645-676.

[9]. Das S, Patra AP, Shaha KK, Sistla SC, Jena MK. High-voltage suicidal electrocution with multiple exit wounds. Am J Forensic Med Pathol 2013;34(1):34-7

[10]. Fernando R, Liyanage S. Suicide by electrocution. Med Sci Law 1990;30:219-220

[11]. Dzhokic G, Jasmina J, Dika A. Electrical Injuries: Etiology, Pathophysiology and Mechanism of Injury. Maced J Med Sci 2008;1(2):54-58 